\title{
Exploração Tímbrica em obra para Pandeiro Brasileiro: Composição e Performance
}

\section{Timbre Exploration on a piece written for Brazilian Pandeiro: Composition and Performance}

\author{
iD Vitor Lyra Biagioni \\ Universidade Federal de Uberlândia, Uberlândia, Minas Gerais, Brasil \\ vlyra95@gmail.com \\ iD Cesar Adriano Traldi \\ Universidade Federal de Uberlândia, Uberlândia, Minas Gerais, Brasil \\ ctraldi@ufu.br
}

Resumo: Apresentamos aqui reflexões sobre o processo composicional e interpretativo da obra Três Momentos para Pandeiro Brasileiro, escrita pelo compositor Cesar Traldi em 2020 para pandeiro brasileiro solo e dedicada para o percussionista Vitor Lyra. O objetivo é demonstrar como a utilização de diferentes estratégias de exploração tímbrica no pandeiro tornou possível a criação de um discurso sonoro/musical inovador para esse instrumento tradicional da música popular brasileira. A obra é escrita em três movimentos, e em cada um deles são adotadas estratégias de exploração tímbrica diferentes: preparo do instrumento, técnicas estendidas, acréscimo de instrumentos, seções de improvisação e processos rítmicos complexos. Também são apresentados os desafios interpretativos envolvidos, descrevendo as soluções encontradas pelos autores durante o processo de estudo e performance da estreia da obra realizada em 2020 dentro da programação do PERFORMUS'20, congresso da Associação Brasileira de Performance Musical - ABRAPEM. Esperamos que as reflexões aqui apresentadas possam auxiliar compositores e intérpretes interessados na utilização do pandeiro brasileiro em novos contextos musicais.

Palavras-chave: Pandeiro Brasileiro. Exploração Tímbrica. Composição. Performance Musical. 
Abstract: This paper brings a reflection about the compositional and interpretative process of Três Momentos para Pandeiro Brasileiro for Brazilian pandeiro (typical kind of tamborine) solo written by composer Cesar Traldi in 2020, dedicated to the percussionist Vitor Lyra. Our goal is to demonstrate how different techniques regarding exploration of timber on the pandeiro enables the creation of an innovative sonorous/ musical discourse for this instrument, going beyond its basic rhythmic accompaniment role in Brazilian popular music. We structured the piece in three movements to approach different strategies for the exploration of timber: instrument preparation, extended techniques, instrument addition, improvisation sessions and complex rhythmic processes. We present the interpretative challenges as well, in order to describe the solutions found by the authors during the process of study and performance for the premier in 2020 within the PERFORMUS'20 congress program held by ABRAPEM (Associação Brasileira de Performance Musical). Our hope is that these reflections can assist composers and interpreters who are interested in the use of the Brazilian pandeiro in new musical contexts.

Keywords: Brazilian Pandeiro. Exploration of Timber. Composition. Musical Performance.

Submetido em: 15 de março de 2021

Aceito em: 9 de setembro de 2021 
Exploração Tímbrica em obra para Pandeiro Brasileiro: Composição e Performance Vitor Lyra Biagioni · Cesar Adriano Traldi

\section{Introdução}

A obra Três Momentos para Pandeiro Brasileiro foi escrita em janeiro de 2020 pelo compositor Cesar Traldi e dedicada ao percussionista Vitor Lyra, ambos autores deste trabalho. A composição para pandeiro brasileiro solo é dividida em três movimentos, nosquais diferentesestratégias deexploraçãotímbrica foram utilizadas para criar o discurso musical. Tradicionalmente, dentro da música popular brasileira, este instrumento tem como principal característica realizar um acompanhamento/marcação rítmica para os instrumentos melódicos e harmônicos.

O objetivo da reflexão sobre o processo composicional e interpretativo da obra Três Momentos para Pandeiro Brasileiro é demonstrar como diferentes estratégias de exploração tímbrica serviram para guiar o discurso musical de uma obra para pandeiro brasileiro solo colocando o instrumento em um novo contexto sonoro/musical e, ao mesmo tempo, refletir sobre os desafios interpretativos vinculados.

Silva (2014) apresenta o processo colaborativo realizado com compositores para a criação de sete obras inéditas para instrumentos marginalizados (bumbo, folha de flandres, geofone, gongos de Pequim, rugido de leão, tamborim e zabumba). Segunda a autora, o termo marginalizado foi criado por Stasi (2012) para tratar da essência marginal do reco-reco, mas em seu trabalho o termo foi utilizado "de forma expandida, para definir instrumentos de percussão que se enquadrem nas condições a seguir: não possuem múltiplas técnicas instrumentais codificadas e/ou não tem uso arraigado na música ocidental de concerto e/ou não tem repertório solo consolidado" (Silva, 2014, 28).

Após uma breve contextualização do surgimento, utilização e repertóriodopandeirobrasileiro, iremosapresentarseparadamente os três movimentos da obra: 1) descrevendo as explorações tímbricas utilizadas; 2) discutindo os conceitos envolvidos; 3) refletindo sobre o processo composicional; e 4) apresentando os 
Exploração Tímbrica em obra para Pandeiro Brasileiro: Composição e Performance Vitor Lyra Biagioni · Cesar Adriano Traldi

desafios interpretativos e as soluções encontradas. Finalizamos refletindo que foi possível criar um discurso musical inovador para o pandeiro brasileiro através das diferentes técnicas de exploração tímbrica utilizadas e que os instrumentistas precisam estar aptos para adaptar sua postura interpretativa aos desafios decorrentes.

\section{Pandeiro Brasileiro}

Rodrigues (2014) apresenta as origens históricas do pandeiro e demonstra sua presença já na chegada dos portugueses ao Brasil através de iconografias do início do período colonial, nas quais escravos foram retratados segurando os instrumentos, além disso, existem registros de que esses instrumentos foram utilizados na catequização indígena.

Existe uma grande variedade de pandeiros pelo mundo, já que em diferentes regiões, países e culturas ele passou por modificações, ganhando características específicas. Assim, o termo pandeiro brasileiro refere-se ao pandeiro utilizado na música popular brasileira e que possui características únicas quando comparado com outros, como o pandeiro sinfônico (utilizado nas orquestras), o daff (instrumento persa muito utilizado na dança do ventre) etc.

O pandeiro brasileiro teve sua origem dos frame drums ${ }^{1} \mathrm{e}$ apresenta características físicas semelhantes ${ }^{2}$, entretanto, com características específicas. Segundo Rodrigues (2014, p. 73), "é muito comum encontrarmos no Brasil os pandeiristas segurando o instrumento na posição horizontal, uma raridade entre os frame drums, mas uma marca característica da execução do pandeiro no Brasil, principalmente nos centros urbanos."

\footnotetext{
1 Frame drum: Expressão inglesa - Nome dado ao "tambor" em que o "casco" não tenha muita altura (entre 0,5" e 3") assemelhando-se a uma moldura, sendo possível segurá-lo com uma das mãos. Refere-se a qualquer tipo de "tamborete", como, os "pandeiros" e o "tamborim". (FRUNGILLO, 2003, p. 127).

2 [...] Possui uma "pele" presa a um "casco" feito de madeira ou metal, podendo ser encontrado também de bambu (bambusa vulgaris") e "cabaça". Nesse "casco" são presos materiais (geralmente de metal) que produzem som pelo entrechoque quando o instrumento é sacudido. Podem ser argolas que se entrechocam ou que se choquem contra o "casco", "guizos", mas o mais comum é que sejam encaixados pares de discos metálicos ("platinela") em pinos atravessados perpendicularmente em fendas abertas em torno do "casco". (FRUNGILLO, 2003, p. 244).
} 
Exploração Tímbrica em obra para Pandeiro Brasileiro: Composição e Performance Vitor Lyra Biagioni · Cesar Adriano Traldi

O pandeiro brasileiro ganhou notoriedade com a criação e difusão do samba no início do século XX. Não existem registros em forma de partitura da maneira como se tocava o instrumento nessa época, já que era tradicionalmente tocado de maneira espontânea pelos instrumentistas. Assim, os relatos históricos sobre o pandeiro na primeira metade do século XX são normalmente relacionados aos intérpretes. Entre os principais nomes que ajudaram no desenvolvimento da linguagem do instrumento neste período estão João da Baiana, Russo do Pandeiro, Gilberto D’Ávila e Risadinha.

\begin{abstract}
Periódicos das décadas de 1930 a 1950 revelam a proeminência de dois pandeiristas entre aqueles ligados à música de radiofonia e fonografia: João da Baiana e Russo do Pandeiro. Observa-se grande quantidade de menções a ambos, proporcionalmente muito maior que a seus pares, e uma certa legitimação de suas expertises, na forma tanto de elogios concedidos por outros artistas quanto de "eleições" (das quais participaram tanto leitores quanto críticos especializados) para escolha dos melhores instrumentistas da música brasileira. (VIDILI, 2017, p. 82).
\end{abstract}

Na segunda metade do século XX tivemos Jorginho do Pandeiro como um dos principais contribuidores para o desenvolvimento da linguagem do instrumento. O músico teve grande destaque no cenário musical, principalmente como pandeirista do grupo Época de Ouro de Jacob do Bandolim. Entre as inovações de Jorginho do Pandeiro está a realização de um acompanhamento rítmico que dialoga com a melodia da música. Segundo Vidili (2017, p. 149):

Jorginho evidencia, em suas performances, a preocupação constante em tocar seguindo o instrumento solista, muitas vezes interagindo com ele e enfatizando algumas de suas figurações melódicas. O pandeiro, portanto, em sua concepção, não deve se limitar à marcação estrita do ritmo; ele assume um papel dialógico na construção da interpretação da música, trabalhando "junto com eles" (não somente com o solista, mas com o "conjunto todo"), "ligado com o que está acontecendo". 
Exploração Tímbrica em obra para Pandeiro Brasileiro: Composição e Performance Vitor Lyra Biagioni · Cesar Adriano Traldi

Diversos foram os instrumentistas que ajudaram no desenvolvimento técnico do pandeiro durante a segunda metade do século XX, entretanto Marcos Suzano é um dos que mais se destaca. Suzano trouxe grande inovação para a performance do instrumento ao criar a técnica invertida, ampliando as possibilidades musicais do pandeiro e inserindo sua presença em gêneros musicais distintos do samba e choro, como: rock, pop, reggae, música instrumental etc. Segundo Vidili (2017 p. 162-163), a técnica invertida possibilita ao intérprete:

[...] iniciar um padrão rítmico não necessariamente com a parte inferior da mão (por baixo), como é feito normalmente na maioria das formas tradicionais de tocar o pandeiro, mas também com a parte superior (por cima). Constatando que em vários padrões rítmicos, tanto da música do candomblé quanto em alguns gêneros de música pop, ocorre a predominância de sons graves nas posições contramétricas ${ }^{3}$ dos tempos do compasso, Suzano percebeu que, ao inverter a lógica dos toques tradicionais de pandeiro e iniciando o toque por cima, estes sons graves em posições contramétricas passariam a ser automaticamente obtidos pelo polegar, resultando em condição de execução mais confortável. (VIDILI, 2017, p. 162-163).

A gravação de áudio e em seguida o audiovisual foram os principais meios de registro da performance do pandeiro brasileiro durante a segunda metade do século XX. Foi também nesse período que surgiram as primeiras iniciativas para a criação de um sistema notacional para o instrumento, o que tornou possível a criação dos primeiros métodos de ensino e obras escritas. Damos destaque aqui para o método A Percussão dos Ritmos Brasileiros, sua Técnica e sua Escrita: O Pandeiro Estilo Brasileiro (s.d.) e a obra Divertimento para pandeiro estilo brasileiro (1992) escritos por Luiz

\footnotetext{
3 Segundo Sandroni (apud VIDILI, 2017, p. 50), o termo cométricas e contramétricas são definidos em: cométricas, para referência às articulações rítmicas quando ocorrem na primeira e terceira semicolcheias que dividem uma semínima; contramétricas, para referência às articulações rítmicas quando ocorrem na segunda e quarta semicolcheias que dividem uma semínima posições que a teoria musical ocidental chama de síncopes.
} 
Exploração Tímbrica em obra para Pandeiro Brasileiro: Composição e Performance Vitor Lyra Biagioni · Cesar Adriano Traldi

D'Anunciação e o sistema de notação criado pelo percussionista Carlos Stasi para notação de suas composições.

Já no século XXI alguns métodos importantes para a continuidade do desenvolvimento da escrita e ampliação do ensino do instrumento são: Pandeirada Brasileira (2007), escrito por Vina Lacerda, e Pandeiro Brasileiro v.1 (2004) e v.2 (2007), escritos por Luiz Roberto Sampaio. Destaca-se também a obra Cachaçada (2007) de Luiz Roberto Sampaio.

O desenvolvimento do sistema notacional além de facilitar o processo de ensino e aprendizado do instrumento, possibilitou a sua inserção em novos contextos sonoros e técnicos. Um bom exemplo é a obra Ao Léu, composta por Leonardo Gorosito e Rafael Alberto em 2005. Trata-se de um dueto de pandeiros brasileiros em que os autores exploram de maneira inovadora a sonoridade das platinelas ${ }^{4}$ do instrumento. Logo no início da obra existe a indicação de que os intérpretes devem "segurar o pandeiro no antebraço esquerdo e tocar nas platinelas com os dedos das duas mãos"5. Assim, limita-se a dinâmica e a movimentação do corpo do instrumento, trazendo maior precisão rítmica para o que será tocado nas platinelas. Outra sonoridade não tradicional utilizada na obra é o giro da platinela ${ }^{6}$, técnica que causa um prolongamento do som das platinelas.

É neste contexto que apresentaremos a seguir as estratégias composicionais utilizadas na obra Três Momentos para Pandeiro Brasileiro, na qual buscamos novos caminhos sonoros e musicais para esse importante instrumento nacional.

\footnotetext{
4 Platinelas: Adaptação de origem portuguesa para diminutivo de 'platos'. Nome dado aos discos de metal pequenos (entre 1" e 2" de diâmetro), furados no centro no qual se encaixam a pinos presos em instrumentos musicais. São usadas aos pares para que se entrechoquem quando o instrumento é sacudido. (FRUNGILLO, 2003, p. 258).

5 Hold pandeiro on left forearm and play on jingles with fingers of both hands, tradução nossa

6 Spin Jingle, tradução nossa
} 


\section{Três Momentos para Pandeiro Brasileiro ${ }^{8}$}

O pandeiro brasileiro possui variações de diâmetro e materiais de construção, e conforme essas características pode ser mais empregado em determinados estilos musicais. Por exemplo, o pandeiro com pele de couro animal é mais utilizado no choro, sendo muitas vezes chamado de pandeiro de choro, já o pandeiro com pele de nylon é mais utilizado no samba. As diferentes possibilidades de diâmetro criam instrumentos mais graves ou mais agudos. O mais comum é o de 10 polegadas, mas também existem com diâmetro de 10,5, 11 e 12 polegadas. O número de platinelas vai variar de acordo com o diâmetro e fabricante (de 5 a 10 pares).

EmTrês Momentos para Pandeiro Brasileiro, propositadamente não foi indicado qual modelo de pandeiro brasileiro deveria ser utilizado. Assim, permite-se que o intérprete escolha o modelo que mais lhe agrade. Dessa forma, a variedade tímbrica buscada na obra também pode ocorrer quando comparamos diferentes interpretações. O intérprete pode utilizar um mesmo modelo de pandeiro nos três movimentos da obra ou mudar de modelo entre eles.

Escrita em três movimentos, são utilizadas diferentes estratégias de exploração sonora para guiar o discurso musical em cada um deles:

- Primeiro Movimento: Exploração de um pandeiro preparado;

- Segundo Movimento: Técnicas estendidas, acréscimo de instrumento e seções de improvisação;

- Terceiro Movimento: Condução rítmica tradicional do instrumento com exploração de processos rítmicos complexos (quiálteras, mudanças de fórmula de compasso, modulação métrica etc.)

\footnotetext{
7 Performance de Vitor Lyra: estreia da obra realizada dentro da programação do PERFORMUS'20 (congresso da ABRAPEM): https://youtu.be/INjFOrfY-NI?t=459

8 Partitura completa: https://shortest.link/-Tg
} 
Exploração Tímbrica em obra para Pandeiro Brasileiro: Composição e Performance Vitor Lyra Biagioni · Cesar Adriano Traldi

Para os trechos em que os timbres utilizados são os tradicionais do instrumento, adotou-se um sistema de escrita inspirado por Carlos Stasi (vide fig. 1), que, segundo Gianesella (2012), é o sistema mais intuitivo e que tem se tornado o mais utilizado pelos compositores e intérpretes.

\begin{abstract}
[...] desenvolvido pelo percussionista e compositor Carlos Stasi para notar suas próprias peças, propõe uma grafia bastante sintética que facilita a leitura, ao mesmo tempo em que identifica todas as diferentes articulações propostas por ele, utilizando apenas uma linha, onde os sons graves (solto ou abafado) produzidos pelo polegar estão grafados abaixo da linha, e os sons graves produzidos pela ponta dos dedos (abafado e solto) estão grafados acima da linha; e os sons das platinelas sem o grave da pele, produzidos tanto pela ponta dos dedos como pela base da mão, utilizam hastes sem a cabeça da nota, mas o primeiro está grafado acima da linha e o segundo tocando a linha (GIANESELLA, 2013, p.193).
\end{abstract}

Figura 1 - Parte da bula da obra Três Momentos para Pandeiro Brasileiro.

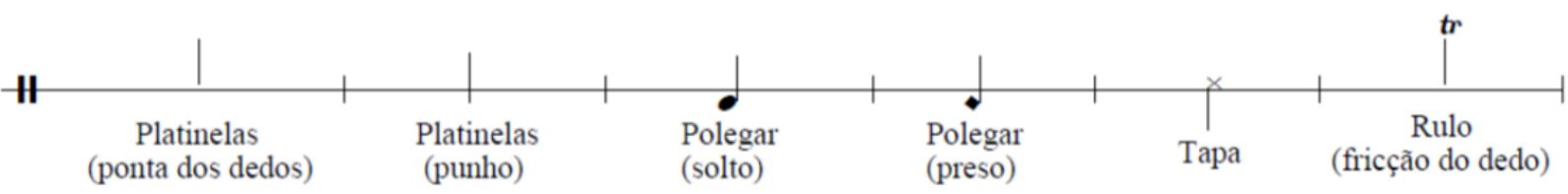

Fonte: autores.

Descrição da imagem: Sistema de notação utilizado para os timbres tradicionais do instrumento

Para a notação das explorações tímbricas utilizadas na obra foi necessário criar novos símbolos, que são descritos nas instruções (bula) da obra (TRALDI, 2020) e serão descritos neste texto sempre que necessário. 
Exploração Tímbrica em obra para Pandeiro Brasileiro: Composição e Performance Vitor Lyra Biagioni · Cesar Adriano Traldi

\section{Primeiro Movimento}

A primeira informação presente nas instruções da obra é que no primeiro movimento será utilizado um pandeiro preparado. A descrição de como deve ser realizado esse preparo também está presente (Pandeiro preparado: fixar guizos de metal nos parafusos de afinação do pandeiro. - Utilizar guizos/sinos utilizados para pescaria). Segundo Costa (2004, p. 19), o conceito de instrumento preparado foi criado por John Cage em 1940 ao utilizar um piano preparado:

Trata-se de um recurso de transformação dos sons de um piano normal, criado pelo compositor norte-americano John Cage (1912-1992) em 1940, em que pequenos objetos como parafusos e borrachas são fixados entre as cordas do instrumento. A ação desses objetos sobre a sonoridade do piano resulta em surpreendentes alterações no timbre. Essas alterações são fruto da maneira como os objetos estão dispostos (em que ponto da corda, em que região do piano, de que modo na corda) e também dependem das características dos próprios objetos (tamanho, peso, espessura, material, etc.) (COSTA, 2004, p. 19).

Existem alguns pandeiros construídos só com pele, outros só com platinelas, mas a maioria dos modelos traz uma combinação entre essas duas sonoridades, ou seja, som metálico e som de pele. Uma das principais características na construção do pandeiro brasileiro, e que o distingue da maioria dos outros pandeiros, é possuir platinelas bem fechadas, limitando sua sonoridade e trazendo maior precisão rítmica. Essa sonoridade das platinelas é somada a uma exploração dos sons da pele, através de variações do timbre e ressonância, por meio da região de toque e pressão dos dedos sobre a pele. Assim, ao acrescentarmos guizos/sinos ao pandeiro brasileiro estamos trazendo duas grandes modificações sonoras ao instrumento: 1) acréscimo de um segundo timbre metálico (junto com o som das platinelas); 2) maior volume e 
Exploração Tímbrica em obra para Pandeiro Brasileiro: Composição e Performance Vitor Lyra Biagioni · Cesar Adriano Traldi

imprecisão rítmica para o som metálico do instrumento. Um fato interessante a ser observado é que o preparo do pandeiro é realizado com um outro instrumento de percussão (guizos) e não com objetos como parafusos e/ou borrachas, como ocorre no piano preparado de Cage. O movimento é marcado por essa preparação, em que o som dos guizos e platinelas criam um ostinato rítmico por todo o movimento.

Para a performance, inicialmente foram aplicadas as técnicas tradicionais do pandeiro, entretanto, a rotação de pulso da mão que segura o pandeiro, normalmente empregada para gerar os sons das platinelas, não gerou a precisão rítmica desejada. Assim, foi necessário adaptar a técnica através de um movimento de cima para baixo do antebraço. Tendo esse ostinato rítmico como uma espécie de pedal durante todo o movimento, uma "melodia rítmica" é desenvolvida através da exploração de diferentes timbres do instrumento.

- Introdução (comp. 01-04): Início do ostinato com a mão que segura o pandeiro crescendo de $\mathrm{p}$ até $\mathrm{mf}$ (que se mantém por todo o movimento).

Figura 2 - Compassos 01 a 04.

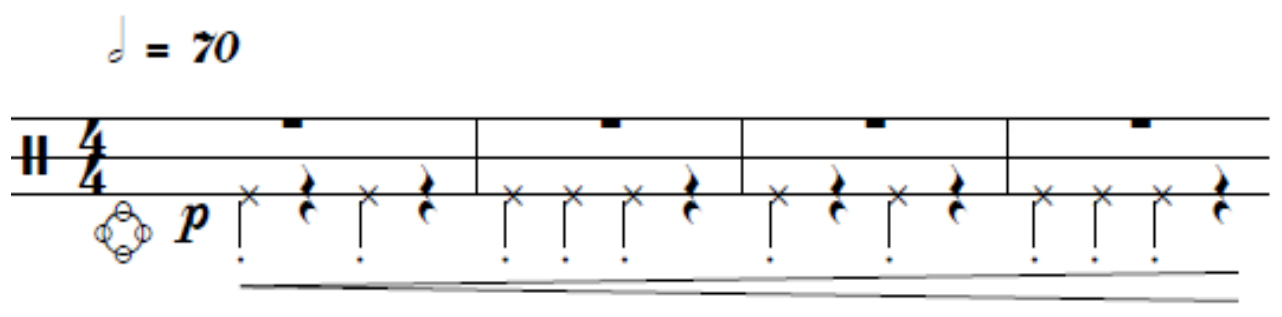

Fonte: autores.

Descrição da imagem: Ostinato rítmico realizado com as platinelas e guizos.

Após uma série de experimentos com tipos e quantidades diferentes de guizos, optamos pela utilização de quatro deles, sendo dois individuais e dois duplos. Assim, não preenchemos os seis parafusos do pandeiro utilizado ${ }^{9}$, mas alcançamos o equilíbrio

9 A quantidade de parafusos de afinação de um pandeiro pode variar dependendo do diâmetro e fabricante. 
Exploração Tímbrica em obra para Pandeiro Brasileiro: Composição e Performance Vitor Lyra Biagioni · Cesar Adriano Traldi

sonoro entre os sons dos guizos e das platinelas que achamos interessante para o ostinato rítmico.

- Seção A (comp. 05-20): Melodia rítmica criada com o toque do dedo indicador na pele e em uma das platinelas.

Figura 3 - Compassos 13 a 16.

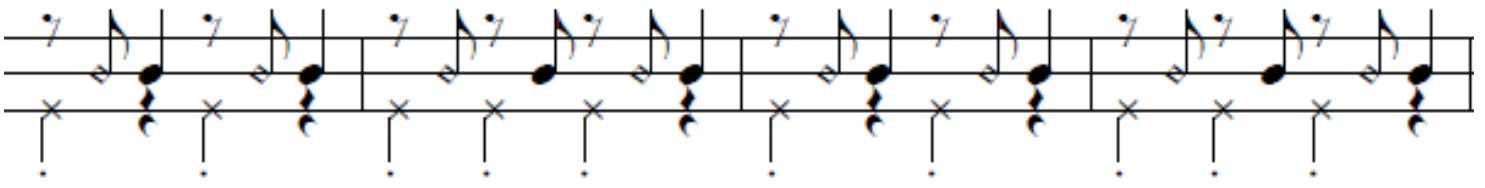

Fonte: autores.

Descrição da imagem: Toque de dedo na pele (cabeça preta) e platinelas (cabeça em forma de losango).

Na performance deste trecho buscamos obter o maior volume possível do som grave da pele, minimizando ao máximo o ataque do impacto do dedo com a pele.

- Seção B (comp. 21-36): Melodia rítmica criada com um caxixi. Apesar da performance de dois instrumentos de percussão ao mesmo tempo, não entendemos se tratar de um trecho de percussão múltipla e sim da utilização de um segundo instrumento (caxixi) para expandir as sonoridades do instrumento principal (pandeiro). Neste sentido, tecnicamente trata-se da performance de dois instrumentos, mas conceitualmente é uma estratégia de expansão da sonoridade do pandeiro solo. É importante aqui destacar que essa concepção dos autores não é consensual e que o trecho pode ser entendido como a performance de percussão múltipla. 
Exploração Tímbrica em obra para Pandeiro Brasileiro: Composição e Performance Vitor Lyra Biagioni · Cesar Adriano Traldi

Figura 4 - Compassos 25 a 28.

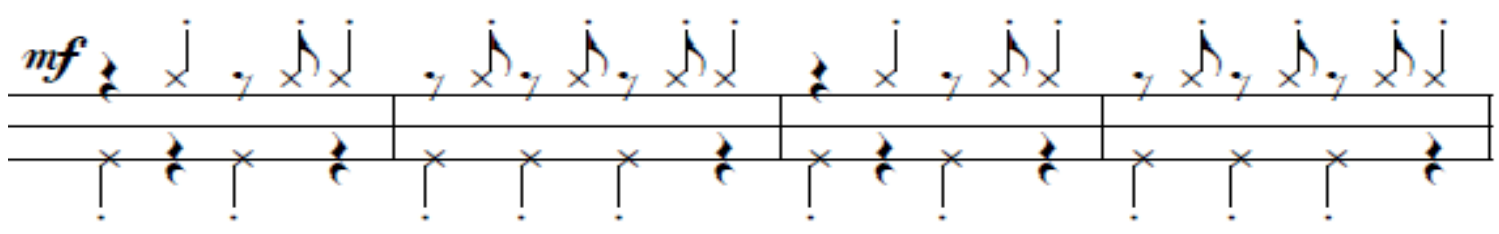

Fonte: autores.

Descrição da imagem: Melodia rítmica com o caxixi (espaço suplementar superior).

Para a performance, optamos por um caxixi que apresentasse uma projeção sonora similar à conseguida na performance do pandeiro nas outras seções do movimento. Escolhemos um instrumento em que a parte inferior é feita de cabaça, o que ajuda na obtenção de um timbre agudo, e com miçangas grandes no seu interior, possibilitando maior precisão rítmica nas passagens.

\section{- Seção C (comp. 37-48): Melodia rítmica realizada com} uma vassourinha ${ }^{10}$ de metal percutindo e raspando a pele do pandeiro. Também são utilizadas notas longas, quando deve se raspar rapidamente na pele (movimento de ida e volta).

Figura 5 - Compassos 37 a 40.

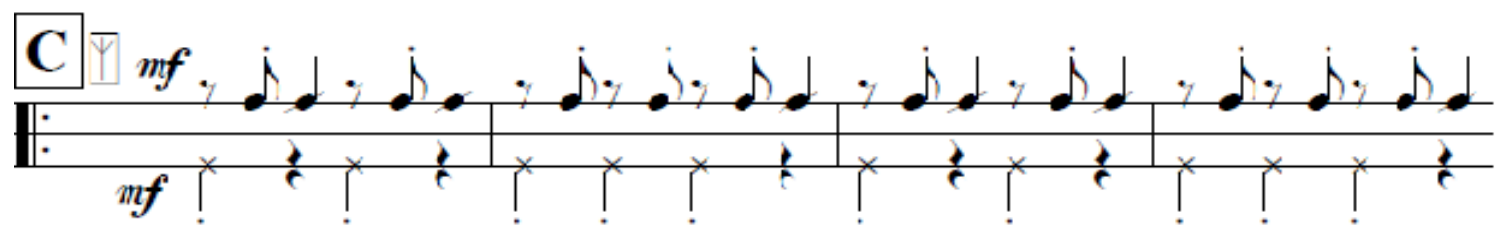

Fonte: autores.

Descrição da imagem: Melodia rítmica com vassourinha (nota pontuada é percutida e cabeça de nota cortada é raspada).

Para a performance deste trecho optamos pela utilização de uma vassourinha com poucas cerdas para facilitar a performance

\footnotetext{
10 Conjunto de fios de arame finos, com o mesmo comprimento (em média 4,5"), amarrados ou fixados numa das extremidades de modo que na extremidade livre as pontas tendem a se afastar, tomando a forma de um ângulo que se abre como um leque ou abano. São utilizadas para percutir instrumentos de "pele" (sobretudo "caixas" e "pratos") pelos "bateristas". Essa técnica de execução, substituindo as "baquetas" tradicionais, teve origem com os instrumentistas de 'jazz', na procura de uma percussão mais suave e de fricção leve da "pele" para acompanhar as frases musicais (FRUNGILLO, 2003, p. 121).
} 
Exploração Tímbrica em obra para Pandeiro Brasileiro: Composição e Performance Vitor Lyra Biagioni · Cesar Adriano Traldi

das passagens com rapidez e clareza. Também foi colocada uma pequena mesa no lado oposto ao da mão que segura o pandeiro para acomodação dos instrumentos e baquetas utilizados em todos os movimentos. Os itens foram acomodados na ordem de utilização, isso facilitou e trouxe rapidez à performance. Foi utilizada ainda uma toalha em cima da mesa como forma de evitar possíveis ruídos das trocas dos instrumentos e baquetas.

- Seção D (comp. 49-56): O ostinato das platinelaséinterrompido e uma frase envolvendo o toque na pele com o dedo indicador e som das platinelas+guizos é realizada em crescendo duas vezes. $\mathrm{Na}$ primeira vez a frase é concluída com um rulo das platinelas+guizos que deve ser realizado sacudindo a mão que está segurando o pandeiro. Essa técnica não é usual no pandeiro brasileiro, sendo bastante utilizada em pandeiros sinfônicos, técnicas tradicionais árabes e italianas.

Na segunda vez a frase em crescendo é concluída com um tapa na pele (ff), finalizando o movimento.

Figura 6 - Compassos 53 a 56.

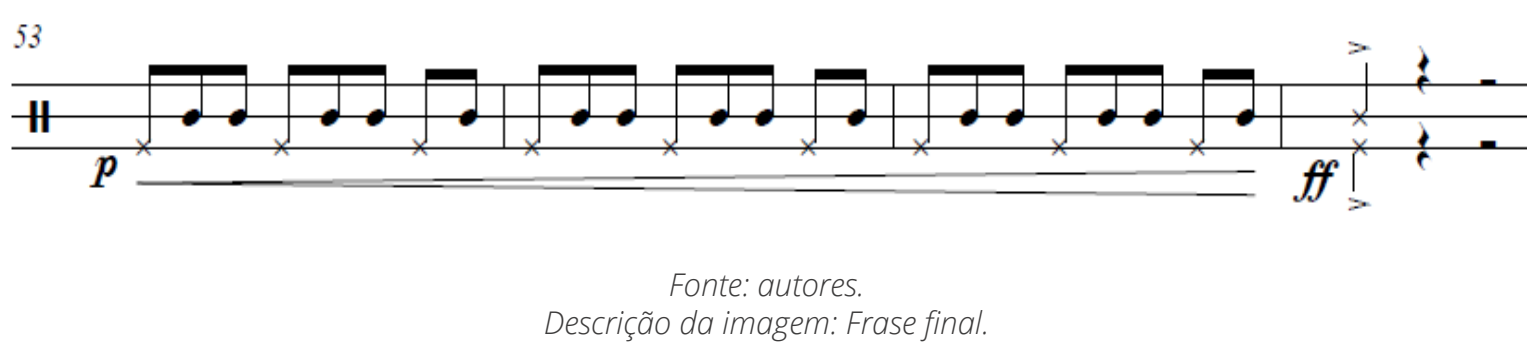

Para o segundo e terceiro movimentos, o pandeiro não deve estar mais preparado. A utilização de dois pandeiros para a performance da obra, em que um fica preparado e o outro não, torna mais rápida e fluente a mudança do primeiro para o segundo movimento, sendo o desejável. Entretanto, na falta de dois instrumentos, é possível a utilização de apenas um, retirando os guizos no intervalo entre os movimentos. 
Exploração Tímbrica em obra para Pandeiro Brasileiro: Composição e Performance Vitor Lyra Biagioni · Cesar Adriano Traldi

Na estreia da obra optou-se pela utilização de dois pandeiros em virtude dessa maior fluidez na troca entre os movimentos, mas também por uma questão sonora. Para o primeiro movimento optou-se por um pandeiro com platinelas mais abertas e agudas, valorizando o ostinato. Já para o segundo e terceiro movimentos optou-se por um pandeiro com platinelas mais fechadas, trazendo uma maior definição rítmica.

\section{Segundo Movimento}

Nas instruções está indicado que antes de iniciar a performance do segundo movimento o intérprete deve:

1) Retirar os guizos do pandeiro preparado, ou trocar de pandeiro se estiver utilizando dois; e,

2) Segurar um prato de dedo com o dedo mínimo da mão que segura o pandeiro. Assim como na utilização do caxixi no primeiro movimento, a utilização do prato de dedo foi pensada como uma estratégia de expandir a sonoridade do pandeiro e não como percussão múltipla. A indicação de que o prato de dedo deve ser segurado pelo dedo mínimo da mão que segura o instrumento tem a intenção de aproximar e facilitar a performance dos dois instrumentos.

O segundo movimento é formado por três seções:

- Seção A (comp. 01-08): Trecho em andamento livre com exploração de diversas técnicas estendidas: performance com baqueta de triângulo no prato de dedo, na platinela, na pele solta e na pele presa; raspagem da baqueta no aro do instrumento; e raspagem dos dedos na pele do instrumento em movimento circular. Segundo Padovani e Ferraz (2011, p 11), "pode-se dizer que o termo técnico estendido equivale a técnica não-usual: maneira de tocar ou cantar que explora possibilidades instrumentais, gestuais 
Exploração Tímbrica em obra para Pandeiro Brasileiro: Composição e Performance Vitor Lyra Biagioni · Cesar Adriano Traldi

e sonoras pouco utilizadas em determinado contexto histórico, estético e cultural".

Figura 7 - Compassos 01 a 08.

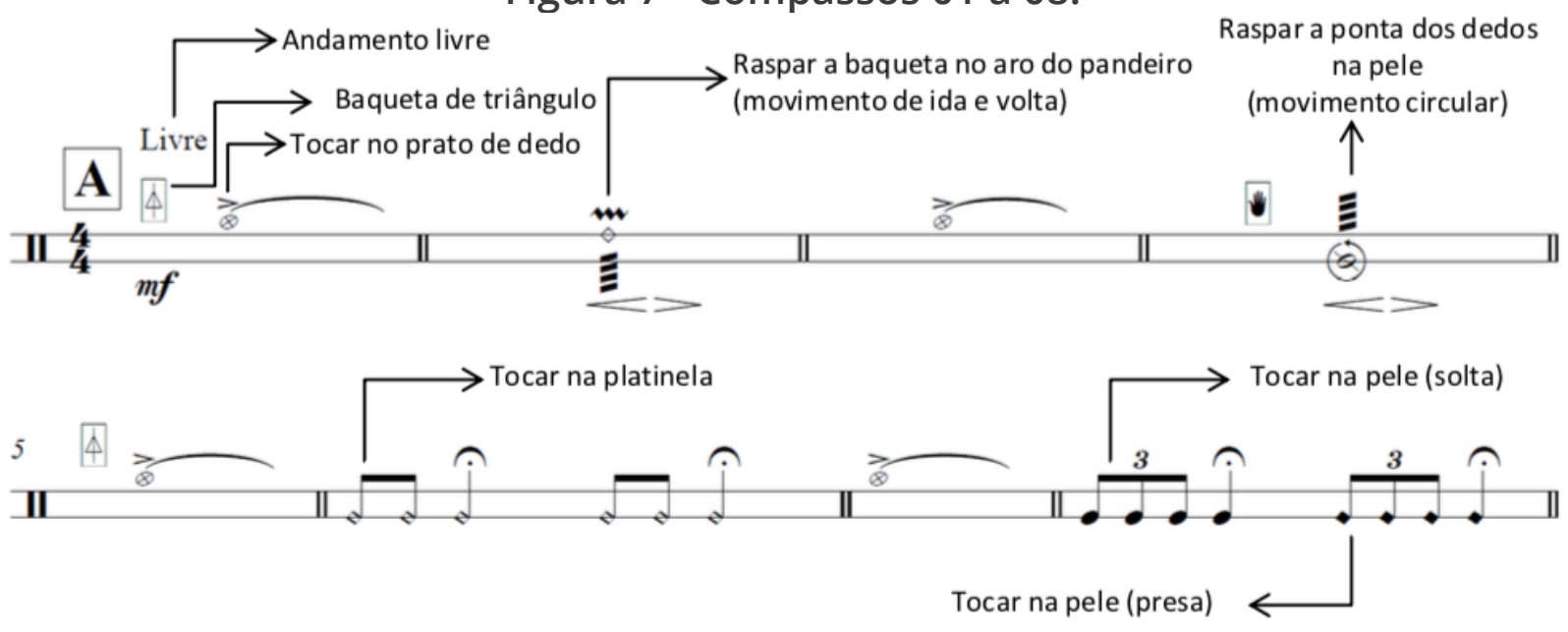

Fonte: autores.

Descrição da imagem: Seção inicial com explicação das técnicas estendidas utilizadas.

Para a performance desse trecho optamos por utilizar uma baqueta de triângulo média, buscando equilíbrio entre a sonoridade do prato de dedo, pele e platinelas do pandeiro.

- Seção B (comp. 09-10): Seção de improvisação com duração aproximada de 30 segundos, na qual é indicado que o intérprete deve utilizar os timbres da seção anterior e acrescentar glissandos realizados através da pressão do polegar na pele (polegar da mão que segura o instrumento). Essa seção é finalizada com a indicação que se deve colocar o pandeiro na vertical e girar uma das platinelas do instrumento.

Figura 8 - Compasso 09 e 10.

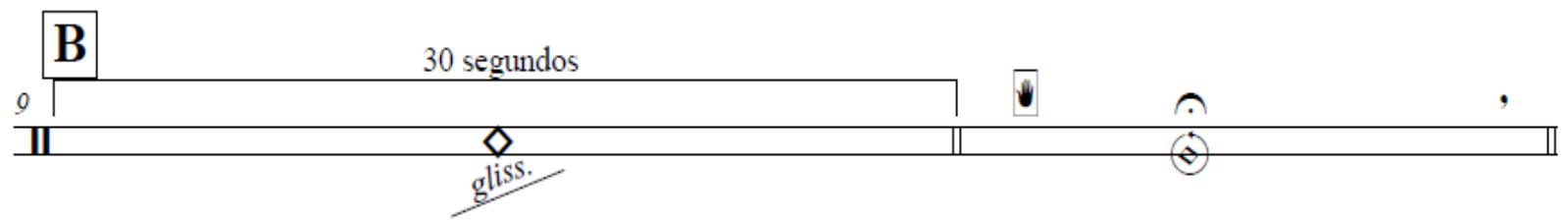

Fonte: autores.

Descrição da imagem: Seção de improvisação e indicação de girar a platinela ao final do trecho. 
Exploração Tímbrica em obra para Pandeiro Brasileiro: Composição e Performance Vitor Lyra Biagioni · Cesar Adriano Traldi

Por se tratar de uma seção improvisada, cada intérprete ou um mesmo intérprete em performances diferentes, terá grande liberdade criativa neste momento. Entretanto, a indicação de se utilizar os sons da seção anterior acrescido de glissandos traz certa uniformidade para as diferentes improvisações possíveis.

- Seção C (comp. 11-12): Segunda seção de improvisação do movimento, deve ter duração um pouco maior que a anterior (40 segundos). Nessa improvisação deve-se utilizar de uma nova técnica estendida, a fricção de uma baqueta superball na pele do pandeiro variando velocidade e evitando interromper o movimento e a fricção. A baqueta superball trata-se de uma baqueta com uma bola de borracha bastante aderente na ponta, assim, quando friccionada em superfícies como a pele do instrumento, faz com que a pele vibre e produza som. De certa maneira a superball consegue produzir em superfícies planas aderentes que possam vibrar o mesmo efeito que o arco produz nas cordas dos instrumentos de corda.

Figura 9 - Compassos 11 e 12.

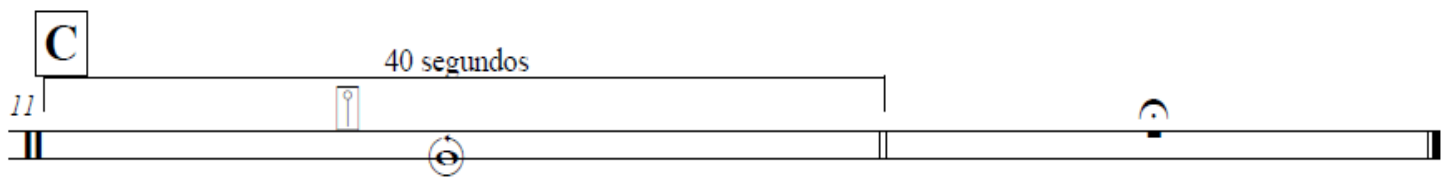

Fonte: autores.

Descrição da imagem: Trecho final com a improvisação utilizando a superball.

Assim como na seção anterior, a improvisação no trecho traz grande responsabilidade criativa para o intérprete. Novamente é indicado o tipo de sonoridade que deve ser utilizado, trazendo certa uniformidade entre diferentes improvisações, ou seja, tratase de uma improvisação controlada.

Para facilitar a performance, principalmente do segundo movimento, previamente foi aplicada cera de abelha na pele do 
Exploração Tímbrica em obra para Pandeiro Brasileiro: Composição e Performance Vitor Lyra Biagioni · Cesar Adriano Traldi

pandeiro. Esse produto facilita a fricção do dedo ou da baqueta superball na pele. A aplicação da cera de abelha na pele do pandeiro é um artifício comumente utilizado pelos intérpretes para facilitar a fricção do dedo na pele, técnica muito empregada no repertório tradicional do instrumento.

\section{Terceiro Movimento}

O terceiro movimento é o que mais se aproxima da linguagem tradicional do pandeiro. Os timbres utilizados e, por consequência, a técnica necessária para se tocar são as tradicionais (vide figura 1).

Para a performance, apesar da partitura indicar apenas a utilização do "som grave" com o polegar solto, optamos pela utilização da técnica invertida de Marcos Suzano, substituindo algumas destas articulações pelo "som grave" realizado com a ponta dos dedos. Essa mudança possibilita que a mão que segura o instrumento movimente-se com melhor fluidez.

O movimento pode ser dividido em 5 seções:

- Introdução (comp. 01-04): Trecho com alternância entre as fórmulas de compasso 4/4 e 5/4, onde valoriza-se o som das platinelas através de acentos e utilização de fusas.

Figura 10 - Compassos 01 a 04.

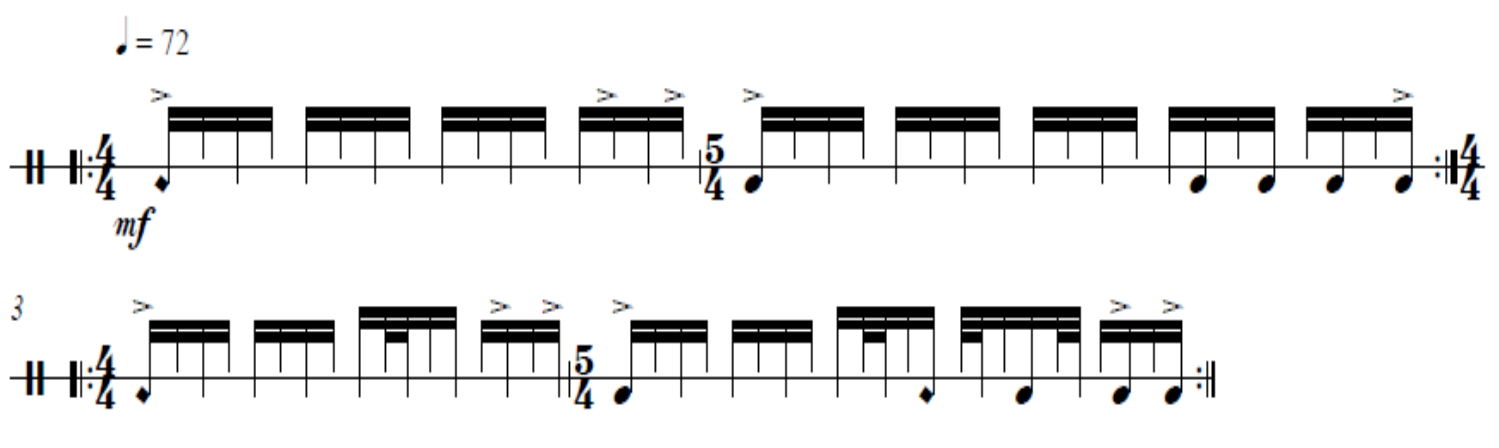

Fonte: autores.

Descrição da imagem: Trecho inicial com fusas e acentos. 
Exploração Tímbrica em obra para Pandeiro Brasileiro: Composição e Performance Vitor Lyra Biagioni · Cesar Adriano Traldi

- Seção A (comp. 05-20): Consolidação da sonoridade tradicional do pandeiro através da combinação dos sons de platinela, pele (aberta e fechada) e tapa. Apesar da utilização dos timbres tradicionais do pandeiro, o trecho foge dos padrões através de mudanças de compasso e do não estabelecimento de um ritmo que se repita por certo período de tempo. A seção é finalizada através de um processo modulatório, que será concretizado em uma modulação métrica na próxima seção.

Figura 11 - Compassos 11 a 16.

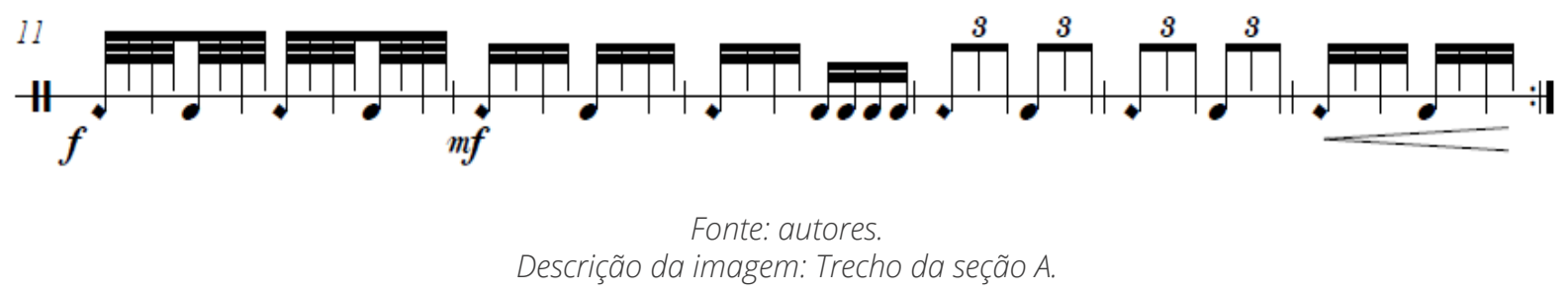

- Seção B (comp. 21- 29): Através de um processo modulatório na seção anterior, a figura de semicolcheia de sextina é utilizada como figura pivô para a consolidação de uma modulação métrica que elevou o andamento da obra de semínima igual a $72 \mathrm{bpm}$ para semínima igual a $108 \mathrm{bpm}$ nesta seção. Segundo Pereira e Traldi (2010, p. 1571), "a modulação métrica é a mudança de um andamento para outro, onde o valor de uma figura do primeiro andamento é equivalente ao valor de uma figura do segundo andamento, como uma espécie de pivô".

Figura 12 - Compassos 17 a 21.

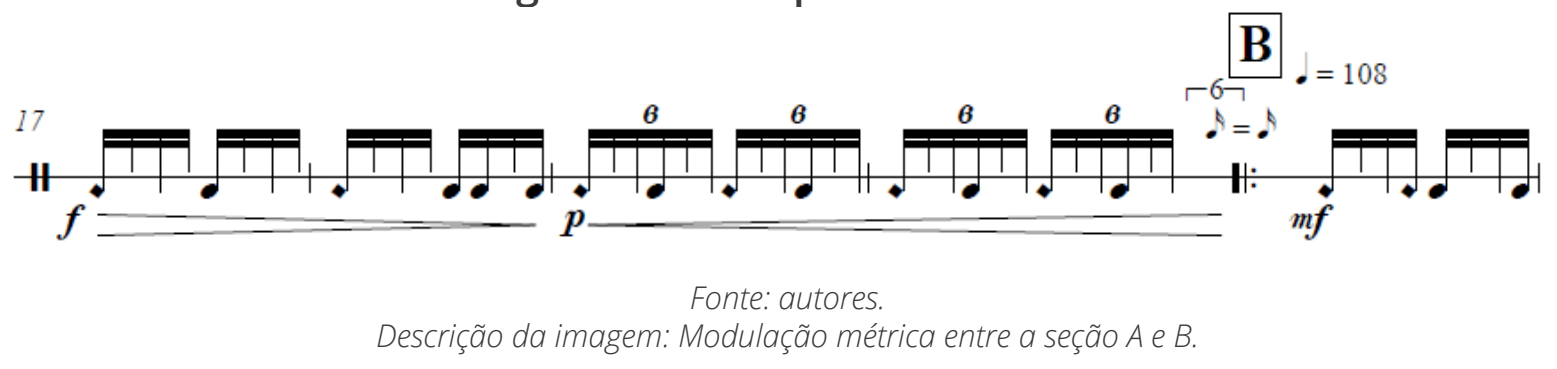

- Seção C (comp. 30): Improvisação livre. Diferente das seções de improvisação anteriores, nas quais existe indicação das 
Exploração Tímbrica em obra para Pandeiro Brasileiro: Composição e Performance Vitor Lyra Biagioni · Cesar Adriano Traldi

sonoridades que devem ser utilizadas durante a improvisação e também do tempo aproximado de duração, nesta seção o intérprete tem total liberdade criativa.

Figura 13 - Compasso 30.

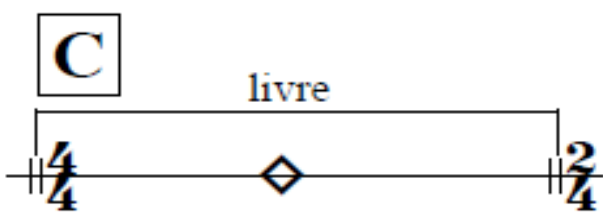

Fonte: autores.

Descrição da imagem: Improvisação livre.

Como forma de ilustrar a improvisação descrevemos o improviso realizado na performance de referência disponível em: https://youtu.be/INjFOrfY-NI?t=849.

$\mathrm{Na}$ introdução da improvisação são realizados toques soltos de polegar, tapas e uma técnica chamada de chicote, em que o instrumentista chacoalha o instrumento com um movimento de antebraço de baixo para cima e faz rimshots na borda com o dedo indicador da mão que está tocando o instrumento. Após essa introdução, são tocadas estruturas rítmicas presentes na seção $A$ e $B$, rulos executados com o polegar ou dedo médio, tapas, toques graves soltos de polegar e utilização de fusas. O improviso continua com estruturas rítmicas da última seção atreladas a crescendos, decrescendos e rubatos. Optou-se por pegar o apito, indicado na última seção da obra, antes da conclusão do improviso, isso trouxe mais fluidez entre o término do improviso e a conexão com a seção $D$. Como forma de concluir o improviso foi realizado um acelerando até chegar no andamento rápido solicitado na última seção do movimento.

- Seção D (comp. 31-46): A última seção da obra foi pensada como um momento de retomada das origens sonoras do pandeiro. Assim, o trecho é todo escrito em fórmula de compasso 
Exploração Tímbrica em obra para Pandeiro Brasileiro: Composição e Performance Vitor Lyra Biagioni · Cesar Adriano Traldi

2/4, executando um ritmo de samba bastante tradicional do pandeiro em andamento de semínima igual a $140 \mathrm{bpm}$. Um apito é acrescentado na performance, remetendo às sonoridades e fraseados de uma escola de samba. A obra é finalizada remetendo a um dos breques mais tradicionais das escolas de samba nos compassos 45 e 46.

Figura 14 - Compassos 42 a 46.

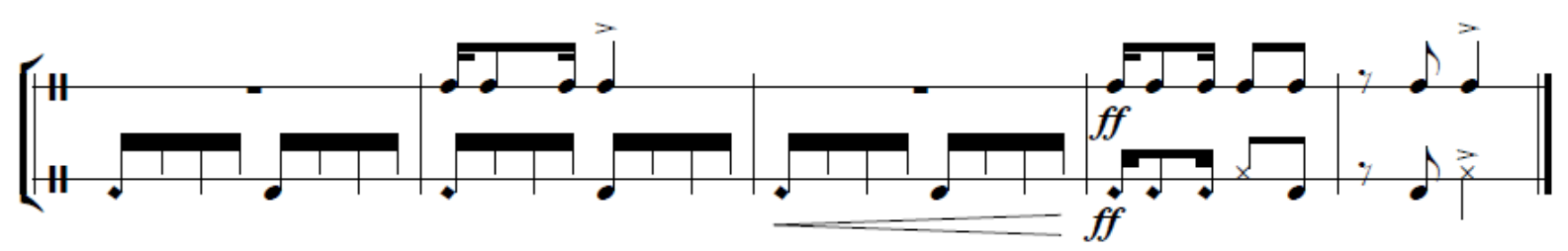

Fonte: autores

Descrição da imagem: Trecho final da obra (pandeiro está escrito na linha inferior e o apito na linha superior)

Para valorizar o término da obra, na performance de referência foi utilizado um movimento para valorizar a última nota da música. Assim, o tapa final foi realizado com o pandeiro levantado na altura da cabeça.

\section{Reflexões e conclusões}

O pandeiro brasileiro é derivado dos frame drums, instrumentos que chegaram ao país durante as primeiras expedições portuguesas. Ao longo de sua história no Brasil o pandeiro passou por modificações na sua construção, técnica instrumental e função musical. Ganhou destaque com o surgimento do samba e do choro no início do século XX. Compacto e versátil, consegue realizar sozinho a condução rítmica de diferentes estilos musicais. Assim, tornou-se um instrumento característico das rodas de samba e um símbolo da música nacional.

A obra Três Momentos para Pandeiro Brasileiro, aqui apresentada, buscou, por meio de diferentes técnicas de exploração tímbrica instrumental, expandir as sonoridades do pandeiro 
Exploração Tímbrica em obra para Pandeiro Brasileiro: Composição e Performance Vitor Lyra Biagioni · Cesar Adriano Traldi

colocando-o em um novo contexto sonoro/musical. Através da reflexão sobre as técnicas de exploração tímbrica utilizadas em cada um dos três movimentos da composição, descrevemos como isso foi possível. Somado a isso, apresentamos reflexões relacionadas às novas necessidades interpretativas desencadeadas por esse processo.

Concluímos que a expansão e exploração tímbrica do pandeiro tornaram possível sua utilização em um novo contexto sonoro e que a apresentação/reflexão sobre as estratégias composicionais adotadas pode contribuir com outros compositores interessados na composição para o pandeiro brasileiro em um contexto sonoro diferente do tradicional, ampliando assim o repertório do instrumento neste contexto.

A reflexão sobre o processo de estudo e performance da estreia da obra pelo percussionista Vitor Lyra demonstram como a utilização de diferentes técnicas de exploração tímbrica no pandeiro brasileiro trouxe novos desafios interpretativos. As soluções encontradas podem contribuir com outros intérpretes interessados em tocar essa obra ou outras composições que envolvam características semelhantes.

\section{Referências}

COSTA, Valério Fiel da. $\mathbf{O}$ piano expandido no século $\mathbf{X X}$ nas obras para piano preparado de John Cage. Dissertação (mestrado), Instituto de Artes da Universidade de Campinas, 2004, Campinas. UNICAMP: Campinas, 2004, 193p.

FRUNGILLO, Mário D. Dicionário de Percussão. São Paulo: Editora da Unesp/ Imprensa Oficial do Estado, 2003.

GIANESELLA, Eduardo Flores. Percussão Orquestral Brasileira. São Paulo: Editora Unesp, 2012. 
Exploração Tímbrica em obra para Pandeiro Brasileiro: Composição e Performance Vitor Lyra Biagioni · Cesar Adriano Traldi

GIANESELLA, Eduardo Flores. O Uso Idiomático dos Instrumentos de Percussão Brasileiros: principais sistemas notacionais para o pandeiro brasileiro. Revista Música Hodie, [S. I.], v. 12, n. 2, 2013. Disponível em: https://www.revistas.ufg.br/musica/article/view/23359. Acesso em: 13 set. 2021.

HENRIQUE PADOVANI E SILVIO FERRAZ, J. Proto-história, Evolução e Situação Atual das Técnicas Estendidas na Criação Musical e na Performance. Revista Música Hodie, Goiânia, v. 11, n. 2, 19 dez. 2012. PEREIRA, Lúcio e TRALDI, Cesar. Modulação Métrica na Obra Canaries de Elliott Carter. In: XX Congresso da ANPPOM, Florianópolis: Editora UDESC, 2010, p. $1570-1575$.

POTTS, Brian J. Marcos Suzano and the Amplified Pandeiro:

Techniques for Nontraditional Performance. Ensaio de Doutorado. University of Miami, 2012.

RODRIGUES, Valéria Zeidan. Pandeiros: entre a Península Ibérica e o Novo Mundo, a trajetória dos pandeiros ao Brasil. 2014. Dissertação (Mestrado em Educação, Arte e História da Cultura). Universidade Presbiteriana Mackenzie, São Paulo, 2014, 155p.

SILVA, Catarina Percinio Moreira da. Sete obras brasileiras inéditas para percussão: concepção, colaboração e o processo de criação de solos para instrumentos marginalizados. 2014. 85 f. Dissertação (Mestrado em Música) - Universidade Federal de Goiás, Goiânia, 2014. STASI, Carlos. O instrumento do diabo: música, imaginação e marginalidade. São Paulo: Unesp, 2012. 116p.

TRALDI, Cesar. Três Momentos para Pandeiro Brasileiro Solo. Partitura. 2020. Disponível em: http://www.numut.iarte.ufu.br/ sites/numut.iarte.ufu.br/files/Anexos/Bookpage/Tre\%CC\%82s\%20 Momentos\%20para\%20Pandeiro\%20Brasileiro.pdf. Acesso em: 14 set. 2021.

VIDILI, Eduardo Marcel. Pandeiro brasileiro: transformações técnicas e estilísticas conduzidas por Jorginho do Pandeiro e Marcos Suzano. Dissertação (Mestrado em Música). Centro de Artes, Udesc, Florianópolis, 2017. 
Exploração Tímbrica em obra para Pandeiro Brasileiro: Composição e Performance Vitor Lyra Biagioni · Cesar Adriano Traldi

\section{Agradecimentos}

Esta pesquisa é parte dos resultados do projeto de pesquisa Percussão e Eletrônicos em Tempo Real: Composição e Performance desenvolvido na Universidade Federal de Uberlândia e financiado pela Fundação de Amparo à Pesquisa do Estado de Minas Gerais (FAPEMIG) e pelo Conselho Nacional de Desenvolvimento Científico e Tecnológico (CNPq).

\section{Publisher}

Universidade Federal de Goiás. Escola de Música e Artes Cênicas. Programa de Pós-graduação em Música. Publicação no Portal de Periódicos UFG.

As ideias expressadas neste artigo são de responsabilidade de seus autores, não representando, necessariamente, a opinião dos editores ou da universidade. 